\title{
Erratum
}

\section{A Logical Model for Predicting Minority Representation: Application to Redistricting and Voting Rights Cases-ERRATUM YUKI ATSUSAKA}

doi: https://doi.org/10.1017/S000305542100054X, Published by Cambridge University Press, 25 June 2021.

$\mathbf{I}$

n Atsusaka 2021, the URL for the replication data contains an error. The correct URL is https://doi. org/10.7910/DVN/F2OX6O.

The publisher regrets this error.

\section{REFERENCE}

Atsusaka, Yuki. “A Logical Model for Predicting Minority Representation: Application to Redistricting and Voting Rights Cases." American Political Science Review. Published online 25 June 2021. https://doi.org/10.1017/S000305542100054X. 